In the drive to the community, it is imperative that adequate provision is made for these severely disabled patients.

Downshire Hospital

OsCar E. Daly

Downpatrick

Co. Down BT30 6RA

N. Ireland

\section{Consultant in mental handicap and resettlement of patients}

DEAR SIRS

Large numbers of long-stay mentally handicapped in-patients are being moved from hospitals to care in the community. Because this is Government and Health Service policy, the practical work involved is often now done by nurses, social workers, resettlement officers and administrative staff who assume the tacit consent of consultant staff. People relocated are usually discharged from direct consultant supervision as they are assigned to the lists of general practitioners. Many do not need continuing psychiatric follow-up - a few undoubtedly will.

If a discharged patient subsequently begins to present problems there may even be a tendency to blame this on the patient's original hospital consultant if the patient has not had specialist out-patient review. When a health authority is making a payment to an agency for the care of a former patient, the authority has a part responsibility to ascertain that the care and treatment of the patient are satisfactory. Therefore, the consultant needs to ensure that a patient leaving hospital has the daily living skills needed for the new environment, is moving out to suitable residential and day facilities, has the compatibility to live with others, and has any psychiatric disorder under control. Well-intentioned carers may seek to have a patient's medication reduced, failing to appreciate that it is treatment which is keeping the patient well.

(The issues in resettlement are reminiscent of 'faith' - the patient's capacity to cope in daily living accomplishments related to the degree of support and care; 'hope'-the patient's opportunity to settle in a suitable environment; and 'charity' - the patient's ability to get along with other people: in practice, the greatest of these is charity.)

The sheet below summarises points which can be used by the psychiatrist as an algorithm, check-list or framework to determine the satisfactory community resettlement of a mentally handicapped person.

DOUGLAS A. SPENCER

University of Leeds

and Meanwood Park Hospital

Leeds LS6 4QD
AlgoRITHM CHECKLIST

Rehabilitation, Relocation, Resettlement

(1) Capability

Social performance: Activities in Daily Living (ADL).

Telling time: by clockface, by events.

Handling money, budgeting: conception of coinage, barter, benefits, savings, bank book

Conception of number: recognition of figures; numerical values.

Literacy: recognition of own name, of signs; ability to follow instructions, understand forms, write own name, write letters.

Personal hygiene, self-esteem: care of teeth, hair, finger nails; belongings; shaving; no stains on clothes.

Use of telephone: private, coin box, emergency, phone cards.

Use of public transport: time table, selecting correct destination, dealing with fares, bus passes.

Domestic duties: planning meals, preparing food, cooking safely - gas, electricity, making beverages, packed lunch.

Laundry: decision to change clothes; hand or machine washing and drying, coin-operated machine, ironing, mending.

Cleaning: own belongings, shoes; changing and making own bed; cleaning own room.

Shopping: ordinary shop, supermarket.

Cafe/restaurant: ordering, self-service, payment.

Road safety: use of pedestrian crossing, traffic lights, signs, Highway Code.

Occupation of free time: leisure, hobbies, clubs, further education classes, library, sports centres; religious activities; holidays.

Seeking held and advice: who to ask, where to go, when to seek.

(2) Care in the community

Residential: NHS Community Unit, local authority social services, adult residential centre (hostel), housing association facility (flat, house), independent sector accommodation.

Staffing: intensity, training, night cover.

Support and advice: community mental handicap teams, advocacy groups, voluntary sector involvement, parents and relatives.

Medical cover: family doctor, specialist, psychiatric oversight.

Day care: adult training centre, hospital department, other day centre.

Transport (payment): coach, taxi, bus.

Funding: 'topping up' by NHS, lump-sum 'dowry' arrangement.

Patient's own allowances and benefits: disablement, invalidity, mobility.

(3) Compatibility

Getting along with others, ability to hold a conversation, co-operative, polite, respecting others' 
rights and property, table manners, ability to rise at correct time, sexual awareness.

Control of any psychiatric symptoms or disabilities

Anxiety, phobias, affective illness, schizophrenia, personality traits, eating disorder, drug abuse, need for specialist psychiatric out-patient follow-up.

\section{Psychiatric medication}

Prescriptions - by GP, side effects, compliance, depot injections - administration by GP, nurse; monitoring of blood levels, e.g., lithium; supplying drug information leaflets to carers.

Other therapies

Counselling, relaxation, others.

General medical conditions and treatments

Epilepsy - blood levels of anti-epileptic drugs, seizure record card; heart, chest, gastrointestinal, genito-urinary, neurological, skeletal disorders; vision, hearing; contraceptive measures.

Dental care

\section{Study leave to attend College meetings \\ DeAR SIRS}

The concern is expressed by junior psychiatrists that there are often considerable difficulties experienced in obtaining study leave to attend College meetings. Unfortunately it appears that, despite previous concern within the College and the JCHPT that attendance at national scientific meetings is a necessary part of training, some senior house officers and registrars cannot obtain the leave and/or funding.

This issue has once more been taken up by the Collegiate Trainees, Committee and, to that end, a survey of the national position was undertaken through regional representatives. The results make interesting reading with large disparities between different geographical areas and training schemes.
The majority of areas have a half-day release course in preparation for the MRCPsych examinations, using up 15 of the allotted study leave days. The availability of time and expenses to attend College meetings and other courses of personal professional interest is therefore reasonably good.

There is the increasing trend, however, for some training schemes, such as those based in Mersey, Leeds, South Manchester and Edinburgh to run their own (e.g. MSc/MPhil) courses. These require a full day commitment per week and can cost the relevant Health Authority up to $£ 1,000$ per year. Such courses of study are more or less compulsory and do not allow trainees the right to determine how their study leave allocation is spent.

Certain regions have more serious problems. One trainee in Basingstoke was not even granted travel expenses to attend the region's own course until the BMA threatened to take court action. Junior psychiatrists in Northern Ireland are severely restricted in their ability to attend meetings in England, and certain Health Boards in Eire do not pay expenses to attend local courses in preparation for the MRCPsych.

In addition, some worrying trends emerge. Study leave is increasingly becoming cash limited with severe constraints placed on juniors only to attend local courses. Pooling of study leave budgets between doctors and, in some cases, all mental health professionals, has led to total non-availability of study leave towards the end of the financial year (Oxford, York).

It is clear that the College should stress, once more, that adequate study leave with expenses, which should include the opportunity to attend College meetings, is a prerequisite for continued approval of schemes for training purposes.

C. P. Lucas

Collegiate Trainees, Committee

\section{Correction}

In the letter entitled 'Models of care for AIDS dementia' (Psychiatric Bulletin, June 1990, 14, 365) reference is made to Professor Beverley Raphael as "he". This is incorrect - Professor Raphael is female. 